\title{
The challenge of restoring dynamics by river engineering: where to find the truth about river flow - in the computer, in the lab or in the field?
}

\author{
Anton J. Schleiss \\ École Polytechnique Fédérale de Lausanne (EPFL), Laboratoire de Constructions Hydrauliques (LCH), Lausanne, Switzerland
}

\section{Extended Abstract}

Rivers are probably the most complex features which we can be found in the environment. They have been and are still the driving force for shaping landscapes and biotopes on our planet. The behavior of river systems is a result of the complex interaction between flow, sediments, morphology and habitats.

"Nature is not to be trifled with, she is always true, always earnest, always severe; she is always right, and the faults and errors are always those of man." (Goethe)

Hydraulic engineers responsible for the planning of river training and restoration works as well as scientists doing river research should bear well in mind this quotation from Goethe. Reliable and sustainable protection against floods can only be assured by hydraulic structures that preserve the natural character of a watercourse during flood events which is often difficult to identify. Accordingly, modern river engineering must take a river's natural forces and behavior into account. For example, attempts to straighten a meander that has developed naturally may be dangerous: in extreme flood conditions, if not earlier, the apparently tamed river will recall and reoccupy the space to which it is entitled [1].

"The world is like a river, running along in its bed, this way and that, forming sand bars by chance and then being forced by these to take a different course. Whereas this all proceeds smoothly and easily and gradually, the river engineers have great difficulties when they seek to counteract this natural behavior." (Goethe)

Goethe (once again) recognized that the dynamics of a river can only be controlled to a limited extent by channel modifications and rigid river training works. The term "dynamics" refers to variations in hydro-morphology over space and time due to flood discharges and sediment transport. These processes regularly lead to the destruction of habitats, especially in riparian areas, and the creation of space for new habitats. Dynamic watercourses require a lot of space. For example, naturally meandering rivers may migrate laterally within a belt of roughly 5-6 times the width of the channel bed. In the valleys of the Alps and Pre-Alps the rivers originally required the entire valley floor.

As well as providing flood protection, watercourse alterations carried out over the last two centuries were designed to reclaim land for development and agriculture. Efforts were thus made to impede the dynamics: rivers and streams were channelized, and channel bed widths were optimized with regard to sediment transport. This resulted in monotonous watercourses, with almost no variation in hydraulic or morphological characteristics.

The today's challenge of river engineers in collaboration with environmental scientists is to restore the channelized river under the constraints of high urbanization and limited space.

The behavior of river systems is a result of the complex interaction between flow, sediments, morphology and habitats. Furthermore, rivers are often also a source for water supply and energy production as well as a waterway for transportation.

"Water is a friendly element for whoever is familiar with it and knows how to manage it." (Goethe)

This quotation from Goethe reminds us that structural flood protection measures need to be based on a detailed knowledge of the processes associated with flooding and of hydro-ecological conditions. In this way, interventions can be kept to a minimum. Even so, river dynamics will inevitably be reduced by flood control structures.

The aim of rehabilitation measures is to restore watercourse dynamics as far as possible, thereby increasing structural diversity. This aim is only attainable if the river engineering measures as river training works are increasing the diversity of flow patterns, which in turn will have favourable effects on the species diversity in the river. Even unavoidable riprap on an almost straight stretch of water should be undulated in such a way as to increase flow diversity. Structural richness always depends on a minimum level of river dynamics, leading, for example, to regular rearrangement of sediments in the channel and local bank erosions.

In this context of flood protection and river restoration, scientists and design engineers are confronted with the challenge to select the appropriate research or design tool in order to give the right answers in view of finding the best sustainable solutions for a certain project or scientific question. Thus, the question arises where to find the truth about river flow: in the computer, in the lab or in the field?

The challenge described above will be illustrated with three examples of research and development projects described briefly in the following. 
The important floods in the years 1993 and 2000 revealed a protection deficit along the Gamsa River in its downstream stretch before its entry in the Rhone [2] [3]. A critical infrastructure, namely a chemistry factory for the production of explosives, was seriously endangered by these floods revealing a damage potential with catastrophic consequences. Based on the event analyses and the local conditions a flood protection project was defined. The river training measures consist of heavy concrete prisms arranged and buried along the river bank as a kind of riprap and groynes. Sediment management and retention completed the protection concept. The constructive protection measures were examined in a large scaled hydraulic model built outdoor closely approximating the behavior of the prototype. The interaction of the concrete prisms with the highly turbulent flow combined with high concentration of sediment transport as well as need of unsteady event simulation, is clearly beyond the potential of numerical simulations.

In rivers, downstream of hydroelectric storage power plants, frequent and intense flow variations occur resulting from peak power production. Subjected to this so-called hydropeaking phenomenon, the fish population suffers from a known decline. In the research of mitigation solutions, shelters in riverbanks may be a protection measure against excessive flow velocities. Such shelters were studied systematically in an experimental set-up with juvenile brown trout, in a channel equipped with a lateral embayment, and supplied with freshwater [4] [5] [6]. The purpose of the experiments was to generate hydrodynamic conditions in the channel that are uncomfortable for fish on one hand and to attract them to the shelter on the other hand. The flow velocity distribution in the intersection between the main channel and the lateral shelter was found to be a significant parameter for the fish attractiveness of the shelter. The utilization rate of fish of the shelter is used as a performance indicator defined as the number of fish present in it compared to the total fish number.

With a basic rectangular shelter configuration, the utilization rate was only of $35 \%$. Introducing a deviation groyne that enforced a water exchange between the channel and the shelter could double this rate. The position and the orientation angle of such groyne have been systematically varied with the purpose of maximizing the frequentation rate. Maximum rates approaching $90 \%$ could be obtained with the best configuration, composing an island type groyne in the shelter. An approach of hybrid modelling was used. First the flow pattern and the hydrodynamic exchange between the main channel and shelter was obtained by numerical simulation for a large number of shelter configurations. Then most promising configurations were tested in a hydraulic model large enough in order to observe the behavior of juvenile trout as under field conditions.

As already mentioned, nowadays flood protection and river engineering projects have to improve also the ecological condition of the river. Very often the space is not available for a full restoration of the river morphology. Therefore, the hydro-morphological heterogeneity has to be optimized within certain space constraints. For such projects a tool for practitioners is very helpful which allows to quantify the habitat heterogeneity enhancement for different project alternatives and to recommend the best alternative in view of eco-morphological perspective.

For overcoming this challenge, a new Hydro-Morphological Index of Diversity (HMID) was proposed, which allows a quantitative statement of the enhancement of habitat heterogeneity during the comparison of different project alternatives in the framework of river engineering projects [7] [8] [9]. Compared to other existing habitat indices, which are mostly based on visual, qualitative assessment in the field and therefore influenced by the subjectivity of the observers, the new HMID is based on statistical parameter calculated by numerical $2 \mathrm{D}$ and $3 \mathrm{D}$ simulations during project planning and thus can be denoted as fully objective.

The HMID was developed on the basis of very extensive field campaigns by recording a large amount of hydraulic and geomorphic data. In order to see the hydro-morphological heterogeneity clearly several very contrasting sites from fully natural to very channelized stretches have been analysed on three different gravel bed rivers in the Swiss Pre-alps. By comparing the variability of the numerous hydraulic and morphological parameters between the studied stretches a formula for the HMID could be proposed. It could be shown that for the investigated river types the coefficients of variation of flow velocity and water depth alone are sufficient to obtain a reliable and predictive HMID.

\section{References}

1. A. Schleiss, Eawag News, 61e, 18-20 (2006).

2. T. Meile, M. Bodenmann, A. Schleiss, J.-L. Boillat, Int. Symposium Interpraevent Riva del Garda, Band 2, 219-230 (2004).

3. T. Meile, A. Schleiss, M. Bodenmann, J.-L. Boillat, M. Jaeggi, Wasser Energie Luft, 97(3/4), 59-66 (2005).

4. J.-M. Ribi, K. Steffen, J.-L. Boillat, A. Peter, A. J. Schleiss, Proceedings of the 33rd Congress of IAHR, Vancouver, Canada, 9.-14. August 2009, CD-Rom, 6074-6081 (2009)

5. J.-M. Ribi, J.-L. Boillat, A.J. Schleiss, River Flow 2010, 8-10 September 2010, Braunschweig, Germany, Ed. Dittrich, Koll, Aeberle \& Geisenhainer (eds), Bundesanstalt für Wasserbau, 665-671 (2010).

6. J.-M. Ribi, J.-L. Boillat, A. Peter, A. J. Schleiss., Aquatic Sciences, 76(4), 527-541 (2014).

7. W. Gostner, Ch. Baumgartner, T. Stäheli, M. Alp, A.J. Schleiss, Ch. T Robinson, Proceedings of the 33rd Congress of IAHR, Vancouver, Canada, 9.-14. August 2009, CD-Rom, 6742-6749 (2009).

8. W. Gostner, M. Alp, A.J. Schleiss, Ch. T Robinson, Hydrobiologia, 712(1), 43-60 (2013).

9. W. Gostner, P. Parasiewicz, A.J. Schleiss, Ecohydrology, 6(4), 652-667 (2013). 